Journal of Applied Pharmaceutical Science Vol. 6 (06), pp. 047-054, June, 2016

Available online at http://www.japsonline.com

DOI: $10.7324 /$ JAPS.2016.60609

ISSN 2231-3354 (cc) BY-NC-SA

\title{
Knowledge, attitude and practice regarding exercise among people exercising in gymnasium and recreational parks around Kuantan, Malaysia
}

\author{
Mohamed Afif Asyraf bin Mohamed Roshdin Murad ${ }^{1}$, Nor Azlina A. Rahman ${ }^{1 *}$, Nor Iza A. Rahman ${ }^{2}$, Mainul Haque ${ }^{3}$ \\ ${ }^{1}$ Department of Biomedical Science, Kulliyyah of Allied Health Sciences, Malaysia. ${ }^{2}$ Unit of Pathology, Faculty of Medicine, Universiti Sultan Zainal \\ Abidin, 20400 Kuala Terengganu, Malaysia. ${ }^{3}$ Faculty of Medicine and Defense Health, National Defence University of Malaysia, Kem Sungai Besi, 57000 \\ Kuala Lumpur, Malaysia.
}

\section{ARTICLE INFO}

Article history:

Received on: 04/12/2015

Revised on: 02/01/2016

Accepted on: 19/03/2016

Available online: 28/06/2016

Key words:

KAP, Exercise, Malaysia.

\begin{abstract}
Physical inactivity is becoming a global epidemic and lead to many diseases. This cross-sectional study tried to investigate knowledge, attitude and practice (KAP) regarding exercise among married and single person attending gymnasium and recreational parks. Furthermore, this study tried to look for factors associated with regularity of exercise and to find association between knowledge and attitude on practice of exercise. A total of 103 participants aged above 18 years old were purposely selected to answer an interview-guided questionnaire. Likert scale was used for participants to answer the questionnaire on KAP and the total score for each knowledge, attitude and practice was computed to find the associations using SPSS. The mean age of the respondent was 25.34 years $(\mathrm{SD}=5.699)$. Knowledge was not significantly associated with practice $(r=0.071, p=0.475)$. There was also no significant correlation between practice and attitude score $(r=0.006, \mathrm{p}=0.510)$. Therefore, there is no association between knowledge and attitude on practice of exercise. Besides that, endurance exercise like jogging, cycling and walking was a respondent's choice as their exercise routine. Other than that, there are significant associations between factors of gender $(p=0.014)$, marital status $(p<0.001)$ and age $(p=0.005)$ with regularity of exercise. This study found that single person is more regularly doing exercise than married people. Regularity of exercise could be influenced by motivation. Therefore, relevant policies and campaigns might be able to change and boost people towards practicing exercise regularly in Malaysia.
\end{abstract}

\section{INTRODUCTION}

Exercise includes a wide range of activities like gardening, car washing or walking around with a pet in the neighborhood and exercise can also be done at home. But some people have a wrong idea that exercise can only be done in gymnasium, recreational park, or a stadium, etc. As long as physical activity causes sweating it is considered as exercise. Muscular contraction during dynamic exercise generates heat which rapidly boosts internal temperature, followed by increasing in perspiration rate (Shibasaki et al., 2006). However, going to sauna and sleeping in hot place can also cause people to sweat but this is not exercise. This is due to evaporative heat loss

\footnotetext{
* Corresponding Author

Nor Azlina A. Rahman, Assistant Professor, Department of Biomedical Science, Kulliyyah of Allied Health Sciences, IIUM Kuantan Campus, Malaysia.Email: nazara@iium.edu.my
}

from human sweat glands, also caused by an exposure to hot surroundings (Shibasaki et al., 2006). Exercise is a subset of physical activity that defined as any body movement produced by skeletal muscles that result in energy expenditure which increases body calorie output and also the heart rate to burn more calories in the body and maintaining physical fitness (PBRC, 2009; Morris and Schoo, 2004). One study claimed that there is no doubt that today's technology is radically altering people's day-to-day life and how people function and think (Oliveira, 2012). These technology causes people to become lazy, decrease of physical activity, unbalanced diet, smoking and drinking alcohol, which are becoming increasingly prevalent in both developed and developing countries (Imbellino, 2014; WHO, 2008). The trend shows modern living provides many conveniences except a natural physical activity. People of all ages use remote controls, ride in cars, play on computers and shop on the internet which causing less muscular actvity (Neporent et al., 2006). 
Furthermore, another study claimed that smoking, high total cholesterol and high blood pressure are strongly related to the development of heart disease and physical inactivity which also lead to a major risk factors for heart disease (Howley and Franks, 2007). One research estimated that nearly $80 \%$ of adult Americans potentially setting themselves to many health problems because of low physical activity (Jaslon, 2013). Physical inactivity is a serious health threat in the USA, which can increase morbidity and mortality (Wright and Winter, 2009).

A regular exercise of three to four times a week for a minimum of 30 minutes each session helps people to stay fit and healthy (CDCP, 2003). Low level of exercise and uncontrolled diet resulted in obesity and weight gain; ultimately increases higher risk of heart disease and diabetes mellitus. Even a short term reduction in regular exercise from 4 to 2 times a week, can cause acute changes associated with diabetes that can occur even before weight gain and obesity (Shy, 2011). Exercising skeletal muscle utilize glucose without insulin and glucose will be burned (Weil, 2015). Exercise helps to lower blood glucose level so that people have lower risk of getting diabetes mellitus.

WHO estimates that approximately 7.6 million people died because of cancer in 2008 and an estimated 13.1 million deaths from cancer will continue to rise in 2030 (Chan, 2013). The common available treatment for cancer is by using chemotherapy. Adverse effects of chemotherapy include sarcopenia, loss of bone mass, and reduction of muscle mass in prostate cancer patient, undergoing an androgen deprivation therapy (ADT) (Galvao et al. 2007). It has been revealed that increase physical activity improves patient's life after receiving a cancer treatment. The study has been conducted on prostate cancer patients receiving ADT with or without exercise. It was found that exercise group had improved endurance and health related quality of life as compared to the non-exercise group (Galvao et al. 2007). Another study conducted on lung cancer found that breathing exercise was an effective way to reduce the post-operative complications of lung cancer ensures better quality of life of the patients (Liu et al., 2013). Cardiovascular diseases can also be prevented with a regular exercise. A study concluded that physical activity is inversely related to cardiovascular disease risks (Thijssen et al., 2008). Exercise reduces around $30 \%$ risk of cardiovascular events like myocardial infraction and stroke (Anderson et al., 2008). Therefore, exercise can assist people to feel healthier and live longer.

Exercise improves people's mood because as it increases the production of endorphin. This hormone is believed to induce happiness, create reward pathway in the brain and reduce pain (Lueneberger, 2006). The life is often stressful, exercise can help to relieve the stress and makes life easier. Therefore, exercise not only improves physical but also mental status. A study reported that regular exercise routine could result in improving mood of the Alzheimer's patients (Williams and Tappen, 2007).

Exercise is very important to keep children healthy, as it prevents extra weight gain and obesity. 30\% of young children aged 2-5 years and 37\% of all children aged 2-years are obese or overweight (Hughes, 2009). Consequently, these children have a higher risk of developing type II diabetes mellitus, heart disease, high blood pressure, asthma, and sleep apnea. Obese children are at greater risk for social and psychological problems of stigmatization and poor self-esteem. However, children who are physically active early in life enjoys high quality of life. A research claimed that women who evaluated the physical fitness of men and muscular body have positively relate it to body attraction which results in mating achievement for the men (Ortega et al., 2011)

In Malaysia, the Malaysian Ministry of Health has launched a nationwide Healthy Lifestyle Campaign in 1991 which includes the objectives to promote exercise as a norm and culture, to disseminate knowledge on benefits of exercise and to increase the proportion of Malaysian to exercise regularly (WHO, 2008). So, all of these measures are very important to promote exercise among people. An adequate knowledge on practicing exercise can encourage people to exercise regularly. A study claimed that $68 \%$ of the women had heard about the advantages of physical exercise during pregnancy (Ribeiro and Milanez, 2011). The purpose of this study is to investigate the knowledge, attitude and practice regarding exercise among married and single person who go to gymnasiums and recreational parks around Kuantan, Malaysia.

\section{MATERIALS AND METHODS}

This study was conducted in Kuantan, Malaysia. It has been conducted among people who practiced exercise in gymnasium, and also recreational parks around Kuantan city. Married and single person were recruited from age 18 years old and above. This was a cross-sectional study based on structured questionnaire. Power and Sample Size Calculations (PS) software was used to calculate the sample size in this study. The calculation using independent t-test, $\alpha$ value is 0.05 , power $=0.8, \delta=3.7, \sigma=$ 6.32 and $\mathrm{m}=1$ that yields 94 subjects $+10 \%$ of nonrespondents $=103$ of the subjects. The standard deviation $(\sigma=6.32)$ mentioned above was taken from the study on Alzheimer's disease (Williams and Tappen, 2007). Therefore, 103 people were selected purposively from gymnasium and recreational parks.

People above 18 years old were included in the study. They were physically healthy to exercise. People who have history of chronic diseases such as hypertension, diabetes mellitus or cardiovascular disease were excluded from the study. Gymnasium instructors were also excluded. Informed consent form and questionnaire were prepared in set of two languages which were in English and Malay languages. The data was collected dated 1001-2014 - 27-01-2014. The questionnaire had been divided into four sections that include questions regarding sociodemographic data, knowledge, attitude and practice regarding exercise. The questions had been constructed randomly and few corrections and amendments had been made to improve the questionnaire. A pilot study had been carried out to check the face validity of questionnaire that involved five people to check the understandability of the questionnaire. The content validity had been checked by an expert. This study had been approved ethically 
by IIUM Research Ethic Committee (IREC). The collected data was analyzed using SPSS software version 12 .

\section{RESULTS}

A total of 103 participants attending gymnasium and recreational parks around Kuantan participated in this study. The participants mean age was 25.34 \pm 5.699 years. $51(50 \%)$ and 52 $(50 \%)$ of study participants were male and female respectively. 68 $(66 \%)$ and $35(34 \%)$ of study participants were single married respectively. $43.7 \%$ (45), $6.8 \%$ (7), $4.9 \%$ (5) and $1 \%$ (1) of participants were full-time workers or students, housewife, parttime, unemployed respectively. $56.3 \%$ (58) and 96\% (99) participants knew the definition of exercise and helps to combat many diseases respectively. While $82.5 \%$ (85), $99 \%$ (102), $84.5 \%$ (87), and $82.5 \%$ (85) understood exercise is able to improve mood, strengthen endurance and stamina, makes life happier and relieve stress respectively. 96-99\% of the participants (99-102) were aware exercise yields a healthy body and fits body (Table 1).
The majority $(83.5 \%, 86)$ of participants have an understanding that exercise causes significant injury. Half of the participants $(50.5 \%, 52)$ disagreed that exercise increases chance of stroke and other circulation problem, remaining $37.9 \%$ (39), and $11.7 \%$ (12) and either agree or disagree respectively. Furthermore, $75.7 \%$ (78), $19.4 \%$ (20), $21.4 \%$ (22), and $15.5 \%$ (16) participants thought that exercise cause people to be exhausted, experience vitamin, iron loss, and thought it as stressful activity respectively (Table 2). The majority $(88.3 \%, 91)$ of the participants choose jogging as their exercise, followed by cycling and walking $(45.6 \%, 47)$, weightlifting $(33 \%, 34)$, swimming $(14.6 \%, 15)$, others $(5.8 \%, 6)$, gardening $(4.9 \%, 5)$ and yoga $(1.9 \%, 2)$.

$53.4 \%$ (55), $90.3 \%$ (93), $88.3 \%$ (91), $50.5 \%$ (52), $48.5 \%$ (50), $87.4 \%$ (90), $41.7 \%$ (43) of the study participants stated that they do exercise for fun, improving health, increasing fitness level, looking good, socializing with others, controlling weight, and motivation from others respectively as the major reason to exercise (Table 3).

Table 1: Knowledge of participants regarding the benefits of exercise $(\mathrm{N}=103)$

\begin{tabular}{lccc}
\hline & & N $(\%)$ & \\
\hline Statements & Strongly Agree and Agree & Neither agree or disagree & Strongly disagree and Disagree \\
\hline Exercise help to combat many diseases & $99(96.1)$ & $3(2.9)$ & $1(1.0)$ \\
Exercise improve mood & $85(82.5)$ & $13(12.6)$ & $5(4.9)$ \\
Exercise strengthen endurance and stamina & $102(99)$ & 0 & $1(1.0)$ \\
Exercise makes life happier & $87(84.5)$ & $13(12.6)$ & $3(2.9)$ \\
Exercise is able to relieve stress & $85(82.5)$ & $12(11.7)$ & $6(5.8)$ \\
Exercise yield healthy body & $102(99)$ & 0 & $1(1.0)$ \\
Exercise fits body & $99(96.1)$ & $3(2.9)$ & $1(1.0)$ \\
\hline
\end{tabular}

Table 2: Knowledge of participants regarding the disadvantages of exercise $(\mathrm{N}=103)$.

\begin{tabular}{|c|c|c|c|}
\hline \multirow[b]{2}{*}{ Statements } & \multicolumn{3}{|c|}{$\mathbf{N}(\%)$} \\
\hline & $\begin{array}{c}\text { Strongly Agree and } \\
\text { Agree }\end{array}$ & $\begin{array}{c}\text { Neither agree or } \\
\text { disagree }\end{array}$ & $\begin{array}{c}\text { Strongly disagree and } \\
\text { Disagree }\end{array}$ \\
\hline Significant injuries can occur & $86(83.5)$ & $9(8.7)$ & $8(7.8)$ \\
\hline stroke and other circulation problem & $12(11.7)$ & $39(37.9)$ & $52(50.5)$ \\
\hline Exercise causes people to be exhausted & $78(75.7)$ & $11(10.7)$ & $14(13.6)$ \\
\hline There is vitamin loss after exercise & $20(19.4)$ & $32(31.1)$ & $51(49.5)$ \\
\hline There is iron loss after exercise & $22(21.4)$ & $29(28.2)$ & $52(50.5)$ \\
\hline Exercise is stressful activity & $16(15.5)$ & $9(8.7)$ & $78(75.7)$ \\
\hline
\end{tabular}

Table 3: Attitude of participants regarding the reasons they do exercise $(\mathrm{N}=103)$.

\begin{tabular}{|c|c|c|c|}
\hline & & $\mathbf{N}(\%)$ & \\
\hline Statements & Major reason & Minor Reason & Not a reason \\
\hline Having fun & $55(53.4)$ & $43(41.7)$ & $5(4.9)$ \\
\hline Improving health & $93(90.3)$ & $8(7.8)$ & $2(1.9)$ \\
\hline Increasing fitness level & $91(88.3)$ & $11(10.7)$ & $1(1.0)$ \\
\hline Looking good & $52(50.5)$ & $42(40.8)$ & $9(8.7)$ \\
\hline Socializing with others & $50(48.5)$ & $33(32.0)$ & $20(19.4)$ \\
\hline Controlling weight & $90(87.4)$ & $11(10.7)$ & $2(1.9)$ \\
\hline Motivation from others & $43(41.7)$ & $38(36.9)$ & $22(21.4)$ \\
\hline
\end{tabular}

Table 4: Attitude of participants regarding the reasons they do not exercise $(\mathrm{N}=103)$.

\begin{tabular}{|c|c|c|c|}
\hline & & $\mathbf{N}(\%)$ & \\
\hline Statements & Major reason & Minor Reason & Not a reason \\
\hline Do not have enough time & $40(38.8)$ & $51(49.5)$ & $12(11.7)$ \\
\hline Afraid of getting injured & $15(14.6)$ & $59(57.3)$ & $29(28.2)$ \\
\hline No safe place & $7(6.8)$ & $52(50.5)$ & $44(42.7)$ \\
\hline Have health problem to exercise & $4(3.9)$ & $37(35.9)$ & $62(60.2)$ \\
\hline Do not have partner to exercise & $7(6.8)$ & $62(60.2)$ & $34(33.0)$ \\
\hline Gymnasium membership is expensive & $15(14.6)$ & $51(49.5)$ & $37(35.9)$ \\
\hline Lack of energy and tired & $33(32.0)$ & $47(45.6)$ & $23(22.3)$ \\
\hline Have many responsibilities such as child care and work & $29(28.2)$ & $45(43.7)$ & $29(28.2)$ \\
\hline
\end{tabular}


Table 5: Attitude on the importance level of exercise type ( $\mathrm{N}=103)$.

\begin{tabular}{|c|c|c|c|}
\hline & & $\mathbf{N}(\%)$ & \\
\hline Statements & Very Important & Moderate importance & Not very important \\
\hline Endurance exercise such as jogging & $89(86.4)$ & $13(12.6)$ & $1(1.0)$ \\
\hline Strength such as weight lifting & $22(21.4)$ & $58(56.3)$ & $23(22.3)$ \\
\hline Flexibility such as stretching & $42(40.8)$ & $40(38.8)$ & $21(20.4)$ \\
\hline Balance such as standing on one leg or tai chi & $42(40.8)$ & $33(32.0)$ & $28(27.2)$ \\
\hline
\end{tabular}

Table 6: Relationship between gender and marital status on regularity of exercise (chi- square test).

\begin{tabular}{lccc}
\hline \multicolumn{1}{c}{ Variable } & Always $(\mathbf{n}=\mathbf{4 6}) \mathbf{N}(\boldsymbol{\%})$ & Seldom $(\mathbf{n}=\mathbf{5 7}) \mathbf{N}(\boldsymbol{\%})$ & Chi-square statistics (d.f) \\
\hline Sex & & & $\boldsymbol{p}$-value \\
$\quad$ Male & $29(63.0)$ & $22(38.6)$ & 6.086 \\
$\quad$ Female & $17(37.0)$ & $35(61.4)$ & $(1)$ \\
Marital status & & & 13.045 \\
$\quad$ Married & $7(15.2)$ & $28(49.1)$ & $(1)$ \\
$\quad$ Single & $39(84.8)$ & $29(50.9)$ & 0.014 \\
\hline
\end{tabular}

Table 7: Comparing age between different regularity of exercise using Independent t-test.

\begin{tabular}{lccccc}
\hline Variables & Always N=46 Mean(sd) & Seldom N=57 Mean(sd) & Mean difference (95\% CI) & t-statistical (df) & $\boldsymbol{p}$-value \\
\hline Age (years) & $23.65(4.270)$ & $26.70(6.347)$ & $3.050(0.965,5.134)$ & $2.904(98.048)$ & 0.005 \\
\hline
\end{tabular}

Table 8: Correlation between knowledge and attitude with practice regarding exercise.

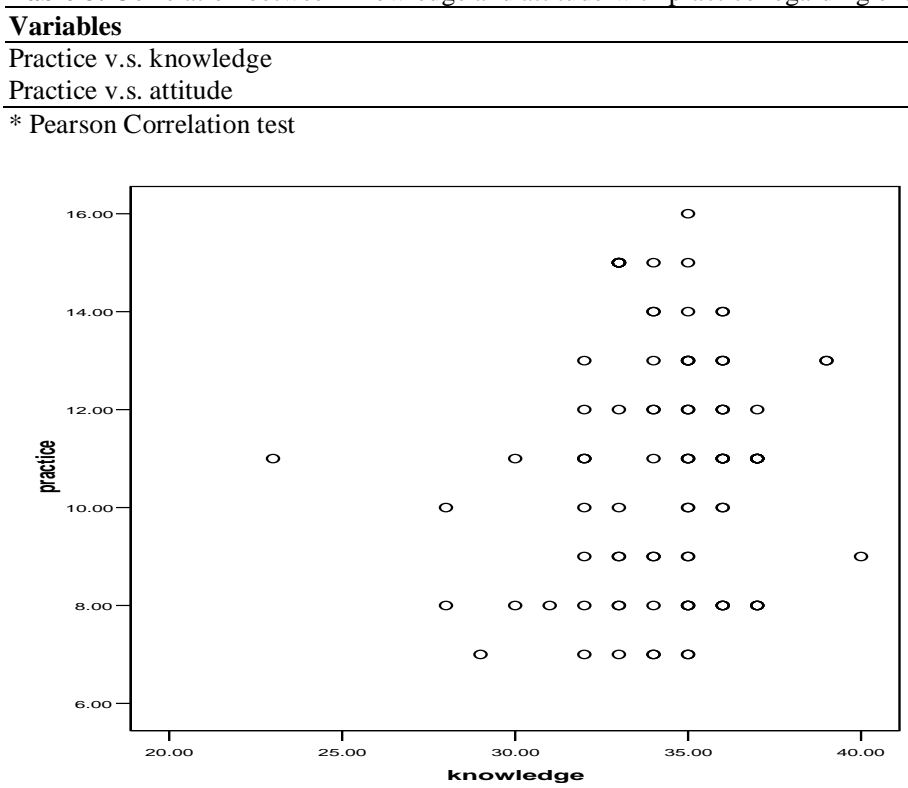

Fig. 1:Correlation between practice and knowledge regarding exercise

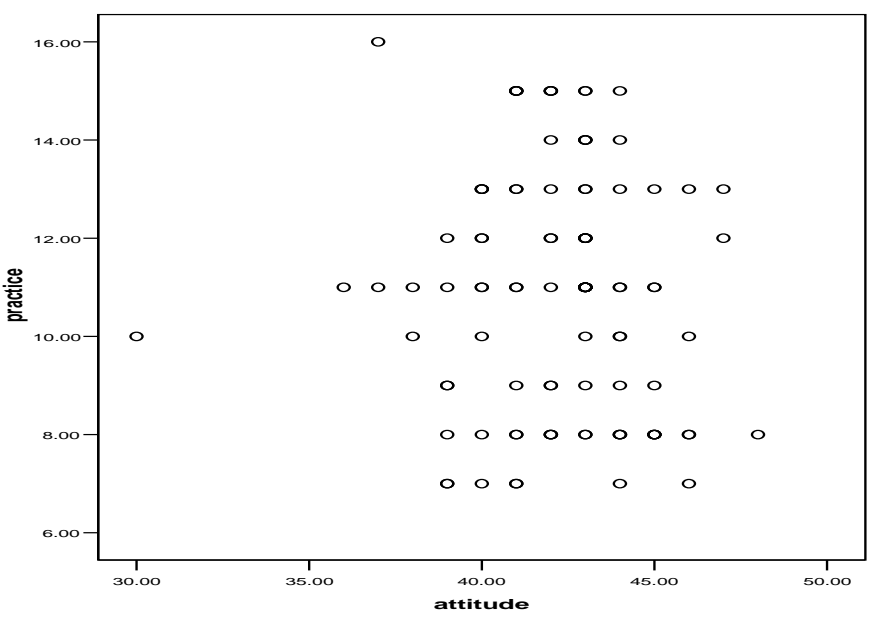

Fig. 2: Correlation between attitude and practice regarding exercise
Again, $38.8 \%$ (40), $14.6 \%$ (15), $6.8 \%$ (7), $3.9 \%$ (4), $6.8 \%$ (7), $14.6 \%$ (15), $32 \%$ (33), and $28.2 \%$ (29) of the study participants answered as their major reason not to do exercise due to lack of time, afraid of getting injured, no safe place, have health problem to exercise, do not have partner to exercise, gymnasium membership is expensive, lack of energy and tired, and have many responsibilities such as child care and work respectively (Table 4).

$99 \%$ (102), $77.7 \%$ (80), $79.6 \%$ (82), and $72.8 \%$ (75) of the participants claimed that endurance exercise such as jogging, strength such as weight lifting, flexibility such as stretching, balance such as standing on one leg or tai chi respectively was moderate to very important to be practiced (Table 5).

$55.3 \%$ (57), and $44.7 \%$ (46) of the study participants answered when asked whether do exercise regularly; answer was: seldom, and always, respectively. Again, 50.5\% (52), 27.2\% (28), and $22.3 \%$ (23) of the study participants answered when asked whether do starching before exercise, answer was: seldom, always, and never respectively. The duration of exercise of the current study participants were $>30$ minutes $(62.1 \%, 64), 20-30$ minutes $(26.2 \%, 27), 10-20$ minutes $(8.7 \%, 9)$, and $\leq 10$ minutes $(2.9 \%, 3)$. The frequency of exercise of our study participant were three times a week $(47.6 \%, 49)$, once a week $(29.1 \%, 30)$, once or twice a month $(11.7 \%, 12)$, five or more time a week $(6.8 \%, 7)$, less often than once a month $(3.9 \%, 4)$, and not at all $(1 \%, 1)$. There were significant associations between gender and marital status (Table 6) with regularity of exercise ( $p=0.014$ and $<0.001$, respectively). Furthermore, there is also a significant $(p=0.005)$ association between age and regularity of exercise (Table 7). There was no 
significant correlation between knowledge and attitude with practice of exercise (Table 8, Figure 1 and 2).

\section{DISCUSSION}

This physical inactivity is associated with an increased risk on morbidity and mortality because of increased risk of developing chronic diseases. According to WHO, almost 2 million deaths per year worldwide are attributable to physical inactivity (Fransson et al., 2012). The occurrence of physical inactivity is thought to be influenced by knowledge and attitude of people on practice of exercise. The majority of participants were young and only a few was old. This is common as the older people face many barriers to exercise. The older people has a number issues like; fear of pain, lack of energy, fear of fall and injury and low education about exercise and health, which compel them to practice more rest. Again, many of them had a health problem because of aging. A study reported similar findings of minimal performance scores, which matches with the study results (Rasinaho et al., 2006).

The young people are concerned with many advantages of exercise and confidence level. It is reported that young women aged 18-30 years became physically active aiming for a positive body image and weight loss. A meta-analysis found that both young women and men were equally concern about good body images and also self-esteem significantly related body image (O’Dougherty et. al., 2010; Mendelson et al., 2002) . Therefore, young people were motivated to exercise in order to lose weight and to look good. This explains why majority of the current study participants were young. It was reported that $>60 \%$ of adults in European were physically active while in the USA it is $>50 \%$ (Teixera et al., 2012). The trend also common in Canada whereby only $15 \%$ of adults were physical active. The current study participants also possess similar ideas and leads physically inactive lifestyle.

The majority of the participants have selected endurance exercise such as jogging, walking and cycling as their exercise routine. It may be because of easier method for different age groups and can be performed anywhere without additional expense. Similar method of exercise was recommended by American College of Sports Medicine and the American Heart Association (Barreira et al., 2010).

There was a significant association between gender and the regularity of exercise. Male usually performed better in exercise than female (Cooper et al., 2011). This is due to the different attitude among genders, males are more committed towards physical exercise (Modolo et al., 2011). Females do exercise because of better appearances. A previous study reported that young girls often have image-related problems which causes them extreme diet and nutritional insufficiency (Modolo et al., 2011, Chin et al., 2008).

There is a significant association between marital status and the regularity of exercise. This is because married people have many commitments and responsibilities towards their families and work. These findings are similar with another study regarding marital status and exercise (Hull et al., 2010). There was a significant association between age and regularity of exercise. This might be due to a low level of awareness among the older people. One study reported that the older community participants were aware of exercise and quality of life. Their knowledge regarding the advantages of exercise on cholesterol, diabetes and hypertension were less (Pienaar et al., 2004). Therefore, older people had positive attitude towards exercise but they lack of sufficient knowledge and motivation. The truth is older people need a regular exercise to be healthier as regular exercise may slow down their ageing process (Xu et al., 2006). The older people develops chronic diseases that may cause negative effect in their physical capability (Cooper et al., 2011). Knowledge and attitude can be the most important points on practicing exercise regularly. The current study shows that more than half of the participants knew the definition of exercise. Exercise is defined as a subset of physical activity that is planned, structured, and repetitive for a physical fitness goal (Caspersen et al., 1985).

Most of the participants in this study were aware of the benefits of exercise. Regular exercise can control blood glucose level and can delay to appear many chronic diseases such as type II diabetes mellitus and cardiovascular diseases (Colberg et al., 2010). Previous study has shown that stroke can be prevented by a good effect of aerobic exercise (Stoller et al., 2012). The patients who suffers from anxiety neurosis, regular exercise reduces their sufferings, improve their mood, and create a sense of happiness (Otto et al., 2007; Steinberg et al., 1997). The current study participants think finds that exercise also strengthens an endurance and stamina. Regular physical activity improves their cardiovascular physiology (Myers, 2003).

The results in this study also shows that majority of the participants were aware that one of the disadvantages of exercise is that significant injuries can occur. A previous research stated that a higher proportion of pregnant women who were injured had participated in at least some vigorous exercise activity during 17 to 22 weeks of gestation than non-injured women (Vladutiu et al., 2010). Besides that, more than half of the participants knew that exercise will not increase a chance of having stroke and other circulation problem. This is mentioned earlier in this study that exercise gave the benefits to reduce the risk of heart attack and stroke due to its ability to improve both oxygen delivery and oxygen extraction in body (Anderson et al., 2008). Furthermore, majority of the participants believed that exercise is not a stressful activity. Exercise has been proven to reduce anxiety and depression (Sharma et al., 2006). Other than that, most of the participants had good knowledge that exercise can cause exhaustion. This is supported by previous research that the diaphragm and abdominal muscles are susceptible to tiredness with heavy and sustained exercise (Romer and Polkey, 2008). However, majority of the participants in this study had negative knowledge about losing vitamins and iron after doing exercise. Actually, intense physical exercise could affect iron balance by a mechanism of increased gastrointestinal blood loss after running 
and hematuria as a result of erythrocyte rupture within the foot during running. Furthermore, the whole-body loss of iron occurs $20 \%$ faster in female athletes as compared to non-athletes (Beard and Tobin; 2000). Moreover, exercise also increases the loss of vitamin B-6, thiamine and riboflavin as these vitamins play a role in producing energy during exercise (Manore, 2000). This study participants, more than half, had the positive attitude regarding exercise and they feel fun. It is reported that exercise enhances mental health. Therefore, increases self-esteem, cognitive function and increased levels of confidence especially in children (Sharma et al., 2006; Eather et al., 2013). This explains why participants had fun after exercise. The study participants agreed that exercise improves their health and fitness level. Previous studies also concluded that exercise was effective in improving cardiopulmonary fitness in asthmatic children and expands their quality of life (Fanelli et al., 2007; Basaran et al., 2006). The current study participants also do exercise to look good and socialize with others. Exercise has been reported to facilitate the symptoms of low self-esteem and social withdrawal (Sharma $e t$ al., 2006). Other research also claims that women evaluated a physical fitness of men and muscular body have positively related to body attraction which results in mating achievement for men (Ortega et al., 2011). Therefore, currents findings were reasonably analogous with the mentioned research reports. The majority of the participants exercise to control and manage their weight. Obese women do exercise to lose weight as primary motivation (Guess, 2012). The combination of exercise and balanced is most effective way to control obesity (Jakicic and Otto, 2005).

However, less than half of the participants exercise due to motivation from others. It has been reported from Canada that motivation influences people to exercise (Duncan et al., 2010). There is a significant relationship has observed between exercise trainer attitude and their customer to join exercise program regularly (Seguin et al., 2010). Moreover, social support also encourage the children to do exercise (Eather et al., 2013). Thus, the motivation from others can also influence people to exercise regularly. Most of the participants answered the reasons they are not exercising were due to lack of energy and time and also feeling of tiredness. Similar, findings were also reported before (Fox et al., 2012). The current study participants opined that they do not have safe place to exercise. A previous study had revealed that some external barriers: not having enough time, have no one to exercise with and lack of facilities and internal barriers: were too tired, already active enough, do not know how to do it and too lazy (Justine et al., 2013).

Surveys had discovered that those residents in lowerincome urban settings are the most likely to rate their neighborhoods as unsafe and crime prevalent (Fox et al., 2012). The majority of the participants did not exercise as they were afraid of injury. Another study reported that $46 \%$ of the exercise participants had at least one injury (Janney and Jakicic, 2010). Furthermore, some pregnant women have reported fear of injury (Vladutiu et al., 2010). An obese individual could potentially face a higher risk of musculoskeletal injury (Campbell et al., 2012).
Same study also reported that exercise may cause injuries but it will eventually promote better health and prevent injuries from other causes (Campbell et al., 2012). Many responsibilities and commitments such as child care and work were the reason more than half of the participants did not exercise. Similar findings have reported in a number of studies (Beckford, 2011; Ebben and Brudzynksi, 2008). The current study participants thought a gymnasium membership was expensive. However, the membership cost cannot be the reason as they can do exercise at any place or home. The participants in this study do not have health problems which can prevent them to exercise. Most of the participants in this study thought that endurance exercise such as jogging wtavas the most important exercise. They however show a slightly negative attitude towards flexibility and balance. It has been reported that different kinds of exercise should combine to get the best outcome especially for the elderly (Anderson et al., 2008; Xu et al., 2006). More than $50 \%$ of the participants seldom practice exercise.

The US population $>50 \%$ meets the current physical activity guidelines (Campbell et al., 2012). Less than half of the participants in this study did a stretching before exercise which it is not a good practice. As mentioned earlier, benefits of stretching include enhance circulation, reduce soreness, improve body awareness and muscular coordination and making body to feel relaxed (Collins, 2007). Therefore, stretching can reduce muscle soreness and can prevent any injury from occurring. The majority of the participants did more than 30 minutes of exercise and they exercise three times a week. The established ACSM guidelines recommended only at least 20 minutes for high-intensity exercise (Klika et al., 2013). So that, 20 to 30 minutes is a suitable duration of time to practice exercise. Furthermore, a minimum of 3 times a week performing exercise is recommended.

There was no significant correlation between knowledge and attitude on practice of exercise. Education can be more effective when it is educated along with attitude and practice of the participants (Salleh et al., 2012). However, it is not necessarily meant that participants with high level of knowledge and good attitude towards exercise will practice exercise regularly. This is supported by other findings regarding women's knowledge, attitude, and practice (Ribeiro and Milanez, 2011). Motivation also plays an important role to encourage people to exercise regularly. The barriers to exercise as described by the pregnant women in the study suggest that many women do not feel motivated to exercise although they were aware of the benefits. Similar findings were also reported regarding pregnancy related health and fetus (Ribeiro and Milanez, 2011).

\section{LIMITATION}

This study was a cross-sectional with purposive sampling, conducted in a few gymnasiums and two recreational parks around Kuantan, Malaysia. Thus, the result may not be giving the reflection of the general population. 


\section{CONCLUSION}

Improving knowledge of the participants can improve their attitude to change their practice to exercise regularly. Therefore, it is indeed an urgent need to further improve the current health intervention programs for better future. Other than that, the study found that endurance training such as jogging and cycling had been selected as favorite routine of exercise. Lastly, there is the relationship between factors of gender, marital status and age with regularity of exercise. It is recommended to do welldesigned prospective multi-centre study to have better understanding in this issue and to provide data for policy makers.

\section{ACKNOWLEDGEMENT}

Authors are much grateful to the study participants who spent their valuable time for this research. Moreover, authors are also indebted to IIUM Kuantan authority for their kindest help in this study.

\section{REFERENCES}

Anderson G, Bates M, Cova S, Macdonald R. 2008. Foundation of Personal Training. United States of America, USA: Canadian fitness Professionals Inc.

Barreira TV, Rowe DA, Kang M. Parameters of Walking and Jogging in Healthy Young Adults. Int J Exerc Sci, 2010; 3(1): 4-13

Basaran S, Guler-Uysal F, Ergen N, Seydaoglu G, BingolKarakoç G, Ufuk Altintas D. Effects of Physical Exercise on Quality of Life, Exercise Capacity and Pulmonary function in Children with Asthma. J Rehabil Med, 2006; 38(2): 130-135.

Beard J, Tobin B. Iron status and exercise. Am J Clin Nutr, 2000; 72(2); 594-597.

Beckford M. Married couples exercise less than single people. 2011. Available from: URL: http://www.telegraph.co.uk/news/health/news/8781716/Married-couplesexercise-less-than-single-people.html

Campbell KL, Foster-Schubert K, Xiao L, Alfano C, Bertram LAC, Duggan C, Irwin M, McTiernan A. Injuries in Sedentary Individuals Enrolled in a 12-Month, Randomized, Controlled, Exercise Trial. J Phys Act Health, 2012; 9(2): 198-207.

Caspersen JC, Powell EK, Christenson MG. Physical Activity, Exercise and Physical Fitness: Definitions and Distinctions for Health-Related Research. Public Health Rep, 1985; 100(2): 126-131.

Centre for Disease Control and Prevention (CDCP). Department of Health and Human Service. Hemochromatosis an Iron Overload Disease You can live a healthy life, if you get treatment early. 2003. Available from: URL: http://www.cdc.gov/ncbddd/hemochromatosis/pdf/ironoverload_508.pdf

Chan C. Strategy on Cancer Control in Hong Kong. 2013. Available from:

URL: http://www.hkacs.org.hk/content/download/Dr_Constance_Chan_Strategy _on_Cancer_Control.pdf

Chin YS, Taib MNM, Shariff ZM, Khor GL. Development of multi-dimensional body image scale for malaysian female adolescents. Nutri Res Pract, 2008; 2(2): 85-92

Colberg SR, Sigal RJ, Fernhall B, Regensteiner JG, Blissmer BJ, Rubin RR, Chasan-Taber L, Albright AL, Braun B. Exercise and Type 2 Diabetes. Diabetes Care, 2010; 33(12): 147-167.

Collins P. Stretching Basics: Stretching \& Flexibility for Sport, Lifestyle and Injury Prevention with Australia's Body Coach, Oxford, Meyer and Meyer Sport (UK), 2007.

Cooper R, Hardy R, Aihie-Sayer A, Ben-Shlomo Y, Birnie K, Cooper C, Craig L, Deary IJ, Demakakos P, Gallacher J, McNeill G,
Martin RM, Starr JM, Steptoe A, Kuh D, HALCyon study team. Age and Gender Differences in Physical Capability Levels from Mid-Life Onwards: The Harmonisation and Meta-Analysis of Data from Eight UK Cohort Studies. PLoS One, 2011; 6(11): e27899.

Duncan RL, Hall CR, Wilson PM, Jenny O. Exercise motivation: a cross-sectional analysis examining its relationships with frequency, intensity, and duration of exercise. Int J Behav Nutr Phys Act, 2010; $7: 7$.

Eather N, Morgan PJ, Lubans DR. Social support from teachers mediates physical activity behavior change in children participating in the Fit-4-Fun intervention. Int J Behav Nutr Phys Act, 2013; 10: 68.

Ebben W, Brudzynksi L. The Motivations and Barriers to Exercise among College Students. Journal of Exercise Physiology Online, 2008; 11(5): 1-11.

Fanelli A, Cabral AL, Neder JA, Martins MA, Carvalho CR. Exercise Training on Disease Control and Quality of Life in Asthmatic Children. Med Sci Sports Exerc, 2007; 39(9): 1474-1480.

Fox AM, Mann DM, Ramos MA, Kleinman LC, Horowitz CR. Barriers to Physical Activity in East Harlem, New York. J Obes, 2012; 2012:719140.

Fransson IE, Heikkila K, Nyberg TS, Zins M, Westerlund H, Westerholm P, et. al. Job Strain as a Risk Factor for Leisure-Time Physical Inactivity: An Individual-Participant Meta-Analysis of Up to 170,000 Men and Women. Am J Epidemiol, 2012; 176(12), 1078-1089

Galvao DA, Taaffe DR, Spry N Newton RU. Exercise can prevent and even reverse adverse effects of androgen suppression treatment in men with prostate cancer. Prostate Cancer Prostatic Dis, 2007; 10 (4): $340-346$

Guess N. A qualitative investigation of attitudes towards aerobic and resistance exercise amongst overweight and obese individuals. BMC Res Notes, 2012; 5: 191.

Howley TB, Franks DB. Fitness Professional's Handbook $\left(5^{\text {th }}\right.$ Ed.). China: Human Kinetics, 2007

Hughes D. Best Practice for Physical Activity: A Guide to Help Children Grow Up Healthy. Health \& Prevention Services. 2009 Available from: URL: https://www.nemours.org/content/dam/nemours/ www/filebox/service/preventive/nhps/paguidelines.pdf

Hull EE, Rofey DL, Robertson RJ, Nagle EF, Otto AD, Aaron DJ. Influence of Marriage and Parenthood on Physical Activity: A 2-Year Prospective Analysis. J Phys Act Health, 2010; 7(5): 577-583.

Imbellino D. How Modern Technology is making us Lazy and Stupid! 2014. Available from: URL: http://www.pctechauthority.com/ tech-editorials/how-technology-makes-us-unproductive.html

Jakicic JM, Otto AD. Physical Activity Considerations for the Treatment and Prevention of Obesity. Am J Clin Nutr, 2005; 82 (1 Suppl): 226-229.

Janney CA, Jakicic JM. The influence of exercise and BMI on injuries and illnesses in overweight and obese individuals: a randomized control trial. Int J Behav Nutr Phys Act, 2010; 7: 1.

Jaslon R. CDC: 80 percent of American adults don't get recommended exercise. CBS News. 2013. Available from: URL: http://www.cbsnews.com/news/cdc-80-percent-of-american-adults-dontget-recommended-exercise/

Justine M, Azizan A, Hassan V, Salleh Z, Manaf H. Barriers to participation in physical activity and exercise among middle-aged and elderly individuals. Singapore Med J, 2013; 54(10): 581-586.

Klika B, Jordann C. High-Intensity Circuit Training Using Body Weight: Maximum Results with Minimal Investment. ACSM'S Health \& Fitness Journal, 2013; 17(3), 8-13

Liu W, Pan YL, Gao CX, Shang Z, Ning LJ, Liu X. Breathing exercises improve post-operative pulmonary function and quality of life in patients with lung cancer: A meta-analysis. Exp Ther Med, 2013; 5(4): 1194-1200.

Lueneberger A. Endorphins, Exercise, and Addictions: A Review of Exercise Dependence. Impulse: The Premier Journal for Undergraduate Publications in the Neurosciences, 2006; 1-9.

Manore MM. Effect of physical activity on thiamine, riboflavin, and vitamin B-6 requirements. Am J Clin Nutr, 2000; 72(2): 598s-606s. 
Mendelson BK, McLaren L, Gauvin L, Steiger H. The Relationship of Self-esteem and Body Esteem in Women with and Without Eating Disorders. Int J Eat Disord, 2002; 31(3): 318-323

Modolo VB, Antunes HKM, Gimenez PRB, Santiago ML, Tufik S, Mello MT. Negative addiction to exercise: are there differences between genders? Clinics (Sao Paulo), 2011; 66(2): 255-260.

Morris M, Schoo A. Optimizing Exercise and Physical Activity in Older People, $1^{\text {st }}$ ed, Philadelphia, USA: Elsevier Science Limited, 2004. 107: e2-e5.

Myers J. Exercise and Cardiovascular Health. Circulation, 2003;

Neporent L, Schlosberg S, Archer SJ. Weight Training for Dummies ( $3^{\text {rd }}$ ed.). Indianapolis, Indiana: Wiley Publishing, USA, 2006.

O'Dougherty M, Kurzer SM, Schmitz HK. Shifting Motivations: Young Women's Reflections on Physical Activity over Time and Across Contexts. Health Educ Behav, 2010; 37(4): 547-567

Oliveira M. Technology And Health: Is The Digital World Hurting Us or Making Things Easier? 2012. The Canadian Press. Available from: URL: http://www.huffingtonpost.ca/2012/12/20/technology-and-health_n_2338439.html

Ortega BF, Brown JW, Lee D, Baruth M, Sui X, Blair NS. In Fitness and Health? A Prospective Study of Changes in Marital Status and Fitness in Men and Women. Am J Epidemiol, 2011; 173(3): 337-344

Otto MW, Church TS, Craft LL, Greer TL, Smits JAJ, Trivedi MH. Exercise for Mood and Anxiety Disorders. Prim Care Companion J Clin Psychiatry, 2007; 9(4): 287-294.

Pennington Biomedical Research Centre (PBRC). Exercise and Your Health: Division of Education. Baton Rouge, Louisiana. Pennington Centre, 2009.

Pienaar PE, De Swart M, De Vries M, Roos H, Joubert,G. Physical activity knowledge, attitudes and practices of the elderly in Bloemfontein old age home. SA Fam Pract, 2004; 46(8): 17-19.

Rasinaho M, Hirvensalo M, Leinonen R, Lintunen T, Rantanen T. Motives for and Barriers to Physical Activity among Older Adults with Mobility Limitations. J Aging Phys Act, 2006; 15 (1): 90-102

Ribeiro PC, Milanez H. Knowledge, attitude and practice of women in Campinas, São Paulo, Brazil with respect to physical exercise in pregnancy: A descriptive study. Reprod Health, 2011; 8: 31.

Romer LM, Polkey MI. Exercise-induced respiratory muscle fatigue: implications for performance. J Appl Physiol, 2008; 104(3): 879888 .

Salleh F, Mumu SJ, Ara F, Ali L, Hossain S, Ahmad KR. Knowledge, Attitude and Practice of Type 2 Diabetic Patients Regarding Obesity: Study in a Tertiary Care Hospitals in Bangladesh. Journal of Public Health in Africa, 2012; 3(8): 29-32.

Seguin RA, Economos CD, Palombo R, Hyatt R, Kuder J, Nelson ME. Strength training and older women: A cross-sectional study examining factors related to exercise adherence. J Aging Phys Act, 2010; 18 (2), 201-218.

Sharma A, Madaan V, Petty FD. Exercise For Mental Health. Prim Care Companion J Clin Psychiatry, 2006; 8(2): 106.

Shibasaki M, Wilson TE, Crandall CG. Neural control and mechanisms of eccrine sweating during heat stress and exercise. J Appl Physiol, 2006; 100 (5): 1-29
Shy L. Studies Confirm Exercise's Disease-Fighting Benefits. 2011. Available from: URL: http://www.popsugar.com/fitness/HowExercise-Helps-Prevent-Diabetes-Cancer-Other-Diseases-18870756

Steinberg H, Sykes EA, Moss T, Lowery S, LeBoutillier N, Dewey A. Exercise enhances creativity independently of mood. $\mathrm{Br}$ J Sports Med, 1997; 31(3): 240-245.

Stoller O, De Bruin ED, Knols RH, Hunt KJ. Effects of cardiovascular exercise early after stroke: systematic review and metaanalysis. BMC Neurol, 2012; 12: 45.

Teixera PJ, Carraca EV, Markland D, Silva MN, Ryan RM. Exercise, physical activity, and self-determination theory: A systematic review. Int J Behav Nutr Phys Act, 2012; 9: 78.

Thijssen DHJ, Maiorana AJ, O'Driscoll G, Cable NT, Hopman MTE, Green DJ. Impacts of In physical Activity and Exercise on The Vasculature in Humans. Eur J Appl Physiol, 2008; 108(5): 845-875.

Vladutiu CJ, Evenson KR, Marshall SW. Physical activity and injuries during pregnancy. J Phys Act Health, 2010; 7(6): 761-769.

Weil R. Managing Your Blood Glucose during Exercise. 2015.

Available from:

URL:

http://www.bd.com/us/diabetes/page. aspx ?cat=7001\&id=7516

Williams CL, Tappen RM. Effect of Exercise on Mood in Nursing Home Residents with Alzheimer's disease. Am J Alzheimers Dis Other Demen, 2007; 22(5): 389-397

World Health Organization (WHO). Review of Best Practice in Interventions to Promote Physical Activity in Developing Countries: Background Document prepared for the WHO Workshop on Physical Activity and Public Health 2005. WHO Press, World Health Organization, 20 Avenue Appia, 1211 Geneva 27, Switzerland, 2008. Available from: URL: http://www.who.int/dietphysicalactivity/bestpracticePA2008.pdf

Wright V, Winter R. Fitness after 40: How to Stay Strong at Any Age. $1^{\text {st }}$ ed., New York, NY: AMACOM, 2009.

Xu DQ, Li JX, Hong Y. Effects of long term Tai Chi practice and jogging exercise on muscle strength and endurance in older people. $\mathrm{Br}$ J Sports Med, 2006; 40(1): 50-54

\section{How to cite this article:}

Murad MAMR, Rahman NAA, Rahman NIA, Haque M. Knowledge, attitude and practice regarding exercise among people exercising in gymnasium and recreational parks around Kuantan, Malaysia. J App Pharm Sci, 2016; 6 (06): 047-054. 